\title{
Quarantined-at-Home Teaching Experience: My E-Learning Plan and Implementation
}

\author{
Azher Hameed Qamar \\ The National University of Sciences and Technology, Pakistan
}

\begin{abstract}
Using my own teaching experience in quarantined-at-home settings, I describe and reflect on my e-learning plan and its implementation. I am teaching two groups of undergraduate students consisting of 80 students. I taught half of the course content during the first half of the semester in a formal university setting. However, after the novel corona breakout, we engaged in online teaching. In line with university guidelines and available support, I initiated my e-learning plan based on blended learning and led by the core objectives to maintain accessibility and quality. Using asynchronous and synchronous modes, I used common and easily available options to enhance two-way teacher-student communication. The feedback that I received after three weeks of implementation of my e-learning plan proved my understanding of the study context as workable and realistic. My conceptual models about the objectives leading the e-learning plan and the implementation model presented in this article can be helpful for the teachers teaching social sciences for the first time in quarantined settings.
\end{abstract}

\section{Introduction}

At first, she admits she was "very skeptical" before she started teaching online. "I felt it was somehow less of a lesson, but now I know that the same amount of preparation goes into both an online and a face to face lesson and the material is also the same." (Speak, 2020, March 31)

The above quote reflects the feelings of a quarantined teacher who is not used to doing online teaching. I used this quote at the start of this article, as this is almost how I am experiencing 
on-line teaching in Pakistan. Doing online teaching in quarantined-at-home settings and continuing it in line with formal regular teaching is demanding and challenging.

A worldwide outbreak of COVID-19 has brought radical changes in social, educational, economic, and healthcare systems across the globe. In most countries, educational institutions were closed after the novel coronavirus outbreak in March 2020. To uphold educational activities, in such a situation, several universities started online delivery of the courses that were taught to regular students in formal institutional settings. At present, teachers are struggling with this drastic shift from traditional classrooms to online classrooms. I am not undermining the struggles students are putting in while experiencing the pedagogical challenges along with other connected challenges, such as access to the required resources for online learning. However, in this article I am reflecting on my experience as a university teacher teaching undergraduate students in psychology. I have already taught half of the semester in a formal classroom setting, and now extensively engaged in online teaching in quarantined-at-home settings. This short article focuses on the challenges I faced and corresponding strategies I used in planning and implementation of online teaching. I am presenting my experience about the progress of the online teaching while meeting the students' expectations and university criteria for quality teaching in social sciences.

This article recognizes the importance of self-reflection of the personal experience of a teacher that can be helpful for academic professionals and policymakers who, in the context of the current situation, are on the same page and experiencing the newness of the teaching-learning process as novices to the quarantined-at-home settings. Even though, I used my knowledge in cognitive and educational psychology; the experience of online teaching presented in this article is contextual and provides insight into my struggle and limitations of my skills and knowledge about establishing online teaching paradigms.

\section{Context of the Study}

The current pandemic situation over the globe proves that online teaching and relevant pedagogical techniques are the only options available to the educational institutions to continue education. Besides challenges associated with the integration of traditional and e-learning format, a feeling of disengagement between teacher and students and procrastination are obvious difficulties in selfregulation faced by the students during online learning (AlJarrah, Thomas, \& Shehab, 2018; Broadbent, 2017; Çakiroglu \& Öztürk, 2017; Chuang, Weng, \& Chen, 2018; Lightner \& LightnerLaws, 2016; Maycock, Lambert, \& Bane 2018; Sun, Wu, \& Lee, 2017). Other difficulties include poor strategies related to time management, online help-seeking and online peer learning (Broadbent, 2017). The reasons behind these difficulties can be linked to increased autonomy to the learners and flexibility of the e-learning structure as compared to formal classroom or face-toface $(\mathrm{F} 2 \mathrm{~F})$ interaction between the students and instructors. In underdeveloped countries the online learning challenges are quite different. Espousal of online learning in these countries is mainly obstructed by access to the internet and issues related to information and communication technology (Ssekakubo, Suleman, \& Marsden, 2011). Lack of proper communication structures, training and quality contents are some other obstructions that cause the failure of online learning implementation in underdeveloped countries (Al-alak \& Alnawas, 2011). The implementation of online learning can reduce the cost of traditional educational settings. On the part of teachers, creating online instructional content to enhance student involvement and engagement requires their robust involvement. Producing and editing online tutorials and making quality content is an exhaustive time-consuming job (Leo \& Puzio, 2016). 
Learning outcomes and effectiveness of online learning can be enhanced by focusing on the adoption of functional strategies by teachers. Proper and regular feedback on assignments and queries, and keeping students informed will keep the learners engaged increasing their attention and response rate on emails (Bailey \& Card, 2009). Professional development is also an efficient strategy to be employed by educational institutions. Adequate training to make use of online platforms, availability of the contact person in case of system breakdown and utilization of learning resources are useful strategies (Crawford-Ferre \& Wiest, 2012; Keengwe \& Kidd, 2010).

Using Roger's (2003) Diffusion of Innovation (DOI) theory, Shea, Pickett, and Lea (2005) found four variables that are strongly linked with the faculty satisfaction in the adoption of elearning are online interaction, availability of technical support, positive learning experience, and course development within study discipline (Shea et al., 2005). Roger's (2003) DOI theory explains the adoption process in five subsequent stages, knowledge, persuasion, decision, implementation, and confirmation. The DOI theory is beneficial in understanding the adoption of technological advancements (Rogers, 2003), organizational culture transitions (Shiflett, 2013), and professional development in higher education (Grosz, 2012). In the current situation, faculty are experiencing a teaching-learning innovation that they have rarely experienced before. Initially, our perceptions about e-learning format during this adoption process are need-based and situational. A gradual process of adoption of e-learning in synchronous and asynchronous modes will expand the blended learning paradigms in formal institutional settings. Even though blended learning, comprised of a variety of learning activities on different digital platforms, enhances cognitive satisfaction and improves the learning process, the literature appears to take F2F interaction in the traditional classroom as an inseparable component of blended learning. Blended learning designs revolve around reduction for formal F2F interaction through increasing asynchronous mode of learning. However, this is also true that the term blended learning does not have a conceptual clarity and has been operationalized in the studies according to the context it is used (Lai, Lam, \& Lim, 2016).

In the current situation, for higher education we need a situation-based and learningfocused solution. In this context, the definition of blended learning may be extended or modified to replace F2F traditional classroom to the virtual classroom combining synchronous and asynchronous modes of learning. Higher education departments all over the world emphasize that institutions need to be properly equipped with modern education facilities including e-learning portals. The technology acceptance model (TAM) predicts the user's most likely positive behavior to use a system if it is useful for him/her and provides ease of use (Davis, 1989). A study using TAM (Mijatovic, Cudanov, Jednak, and Kadijevich, 2013) explored the connections between students' use of a learning management system (LMS), active participation in the class and its effect on students' achievements. The findings were plausible as a positive effect was found on students' achievements where students' interactive use of an LMS and their active participation in the class was reported. This research also showed the use of effective teaching methods, and students' exposure to an e-environment (such as social media) influencing students' active participation and interactive use of an LMS (Mijatovic et al., 2013). Higher education institutes in Pakistan, using LMS, make its use mandatory for teachers and students. Besides developing the LMS as a user-friendly e-learning portal, teachers and students are trained to use the LMS effectively. Hence, the teachers, who are in F2F interaction with the students can play a proactive role in integrating synchronous and asynchronous learning. Nevertheless, flexibility is important at both the institutional level and conceptual level to use blended learning according to the prevailing situation. 


\section{Online Education in Pakistani Universities During Quarantine}

Amid the COVID-19 outbreak, on 13 March 2020, the Pakistan government ordered to close all public/private schools, colleges, and universities. The Higher Education Commission (HEC) of Pakistan (2020a, 2020b) urged and supported universities to go online to continue the academic year as planned. The HEC emphasized using digital platforms and developing (or maintaining) the LMS to support online education. An LMS, as an e-learning tool, is a mobilefriendly platform to manage, regulate, and operate educational activities including content, assignments, quizzes, and recorded lectures. In this regard, the Virtual University of Pakistan (a recognized higher education body providing e-learning since 2002) is supporting universities.

The decision made by the HEC to shift to online classes received mixed feedback. Those who appreciated the decision found it wise to save the time of the students in current unpredictable circumstances. Others argued, saying it was a compromised education that would lack quality. The majority (universities and students) supported the HEC's effort to make good use of time. However, only the top universities with the required infrastructure (such as existing and operationalized LMS) could launch a quality online education. The HEC addressed these issues on two levels: first with respect to the quality, and second related the connectivity (see Figure 1). To ensure quality, the HEC introduced online readiness that includes six components:

1. University Readiness (LMS, ready and operational)

2. Faculty Readiness (trained faculty)

3. Course Readiness (on-line availability of the courses)

4. Library Readiness (online library)

5. Technology Readiness (technical resources required for online education)

6. Student Readiness (comprehensive support and assistance) (HEC, 2020a)

The HEC also introduced four steps to address connectivity issues:

1. Taleem Bundle ('E-education Package' that includes subsidized internet services)

2. Delivery Mode (using both synchronous and asynchronous modes)

3. Offline Mode (Digital data, such as CDs, provided through postal services)

4. Student Facilitation Committee (Committee to address connectivity issues) (HEC, 2020b)

Even though $70 \%$ of public sector universities do not have an LMS and lack university readiness (HEC, 2020), the HEC is making its efforts to implement these two levels in its true sense and supervising the universities to ensure quality online education for all the students. Fortunately, the university I am serving is one of the top-ranked universities in Pakistan and fulfills the criteria set by the HEC for high-quality online education. The National University of Sciences and Technology, maintaining the standard set by the HEC, gives us the flexibility to use options that can facilitate the students equally regardless of their geographical location and the technical resources they have. It means that as a faculty member it is my responsibility to address my students' issues while seeking support from the university and innovatively using all available resources. 


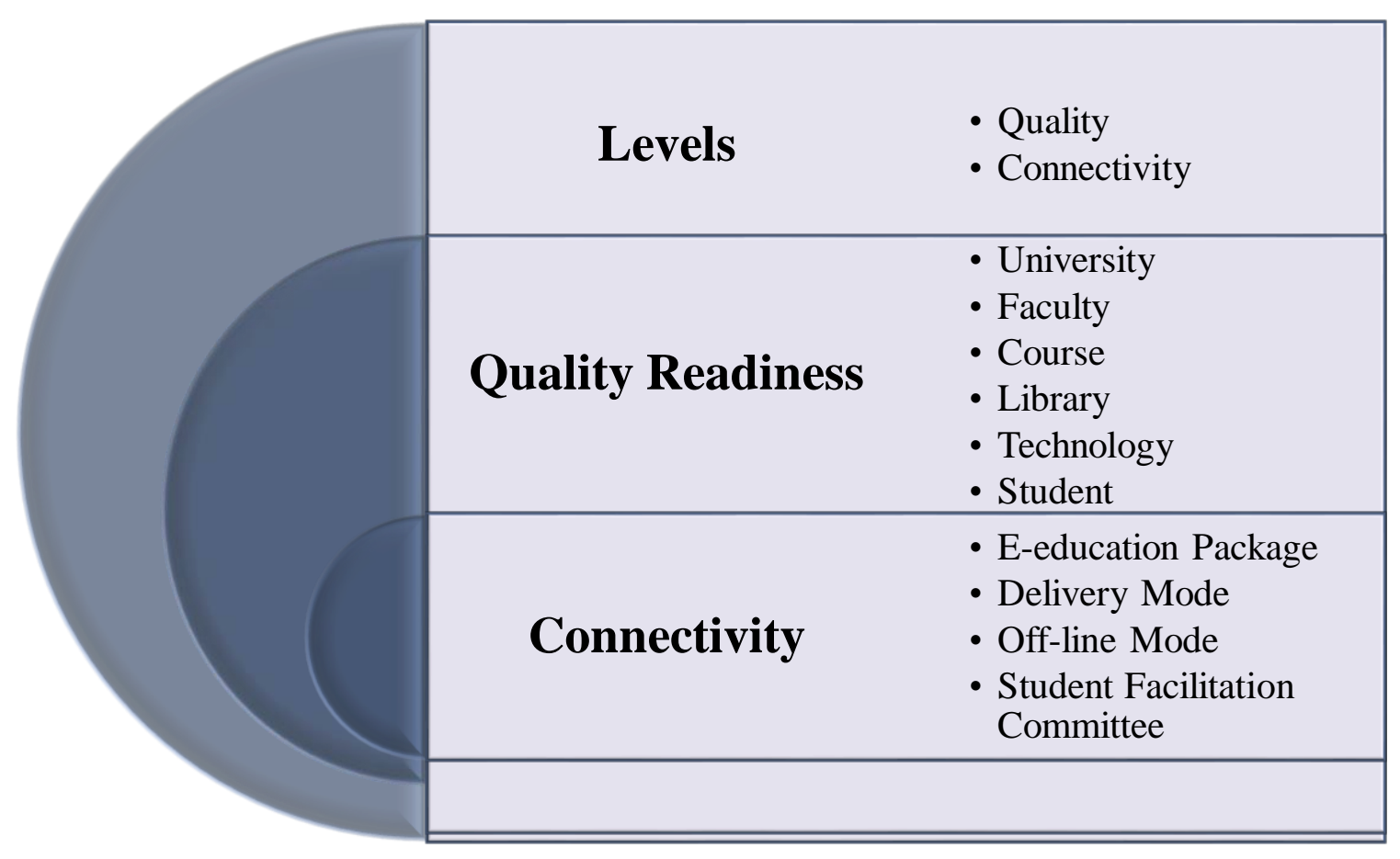

Figure 1: HEC Pakistan's (2020b) plan for online education during quarantine.

Now, I will present my experience of planning and implementing online education in quarantined-at-home settings.

\section{Students Engaged in Online Teaching}

I teach two groups of undergraduate students studying two different courses in psychology. Each group consists of 40 students. In Pakistan, the majority of the students who study psychology are girls. About $90 \%$ of my students are girls. Based on their assessment (before midterm), the majority of the students are average and above average in their performance. I placed students on average and above-average categories who scored between $50 \%-90 \%$ in their assessments. The National University of Sciences and Technology strictly emphasizes merit and follows a rigorous process of admission. The university is a semi-government institute and most of the students belong to middle-class families. About 5\% of students live in far-off areas where they do not have internet facilities. They could not join the online class. The university is working for other alternatives (offline mode) for those students, such as traditional distance education using postal services.

\section{Teaching Context}

In this section I am providing information about the formal setting in which I taught half of the semester, and the quarantined-at-home setting, in which I am currently serving the purpose (probably until the end of the semester). 


\section{Teaching in Formal Settings}

I have been teaching different courses in psychology to university students as a regular faculty member since 2014. Before quarantined life, I was teaching two courses to two undergrad groups. I used to prepare a lecture using online resources available at the campus. I prepared PowerPoint slides with content headlines and classroom activities. It was hard for me to stand behind the rostrum or on the stage throughout the lecture. I used to move around, reaching the students to ask and take questions, and inviting them to come on stage to have a dialogue. Showing video clips on the multimedia projector and asking to write or speak their reflection was an interesting aspect of the F2F teaching in a class well facilitated with whiteboards, multimedia, and comfortable seating for the students. All students were right before my eyes, and I was always in a good position to find the one who was either reluctant to ask a question or missed something. Even passing a relevant joke, sharing a personal experience, and then attending to the facial expressions of the students was practical with F2F teaching. Almost all the questions and answers related to the topic were covered in one interactive session of two hours (once a week) with a 20minute break. The students were also used to it. For them university life has always been a dream life with social interactions, extra-curricular activities, fun, and learning. We did not know that after midterm we were going to experience a drastic change in our academic life.

\section{Teaching in a Quarantined-at-Home Setting}

Moving to teaching in a quarantined setting was a surprise; however, it was not surprising that I could sense the challenges I was going to face. Living in a small house with an informal family environment and the distractions - that in normal days would be a source of fun and entertainment - are the taken-for-granted issues. I managed to solve these issues by occupying a small room in my house for a few hours during the daytime and a few hours in the evening. It helps me to concentrate as I am in my office. I could realize the students' situation at their homes. It was difficult to shift a formal task into an informal setting. I was ready to find a situation-based, learning-focused approach.

I found blended learning (BL) a useful approach to follow in a quarantined-at-home context. BL is an approach to combine traditional and online learning. In addition to F2F learning in traditional classroom environments, computer-based content preparation and delivery enhance the learning environment. BL supports the learning system when the resource personnel and participants are not able to remain in F2F contact and there is an availability of computer and internet (Banditvilai, 2016; McGee \& Reis, 2012; Singh, 2003). BL provides a flexibility to combine different formats of instructions that include (a) synchronous in physical format (i.e., traditional F2F learning), (b) synchronous online format (i.e., live online learning and real-time interaction), and (c) asynchronous format (i.e., providing web-supported material for self-paced learning). All these formats support the process of continuing education (Singh, 2003). In the situation I was facing, to maintain a reasonable connection between formal (regular) and online learning, I opted to use the synchronous online format and the asynchronous format simultaneously. I considered active engagement, cognitive satisfaction, time management and shared understanding (ACTS) as the core objectives that led my blended learning format and ensured active learning (see Figure 2). 


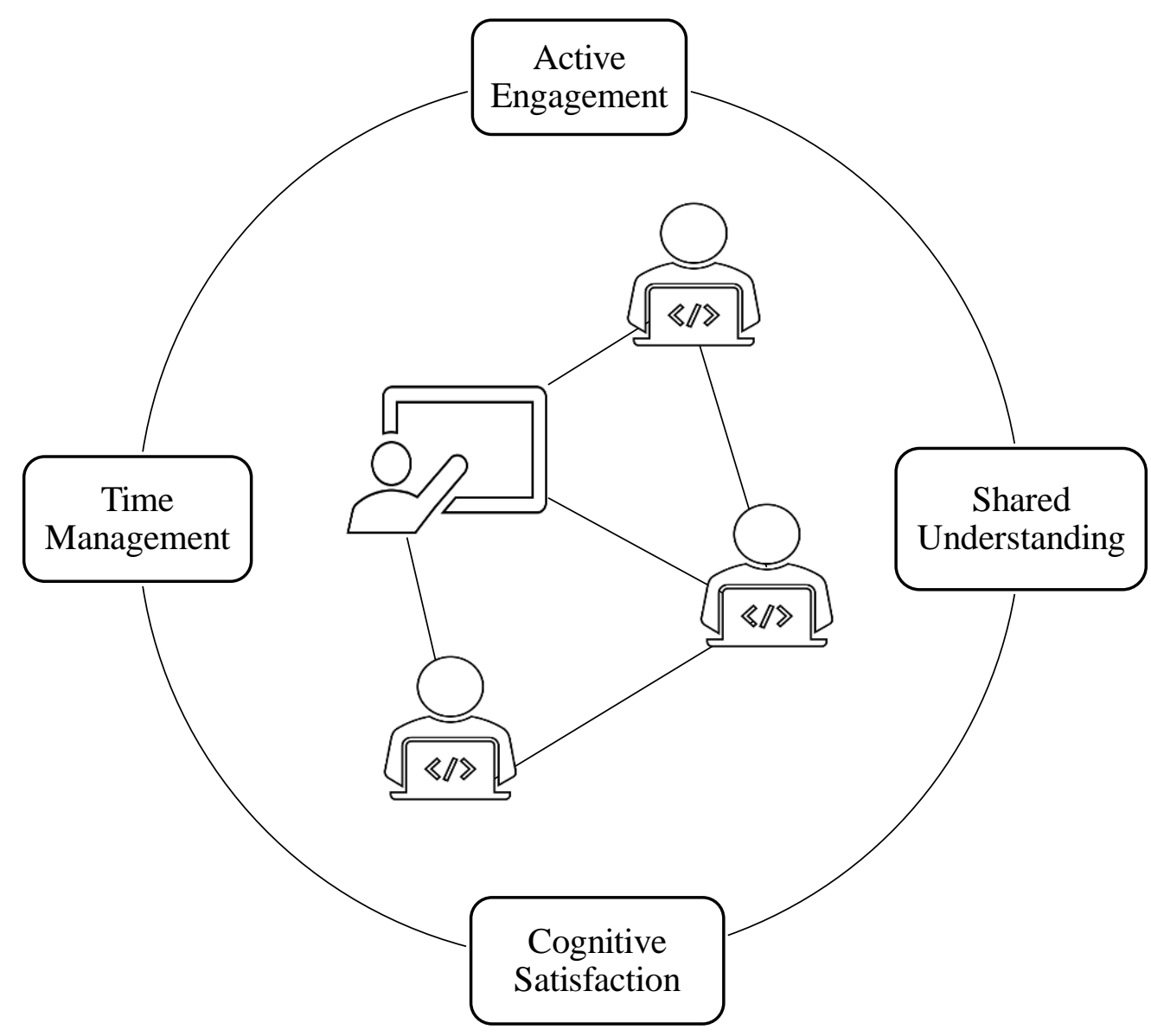

Figure 2: ACTS - Core objectives of my blended learning format.

To meet the core objectives of blending learning, I formulated the following e-learning plan (Table 1).

Table 1. E-learning plan of blended learning during quarantined-at-home teaching.

\begin{tabular}{lll}
\hline & Synchronous online format & Asynchronous format \\
\hline Interactivity & MS Teams* (live), Chat Box & MS Teams, LMS, Email \\
\hline Instructions & MS Teams (live), Chat Box & Email, LMS \\
\hline Language & Bilingual (English-Urdu) & English \\
\hline Lecture/Discussion & MS Teams (live), Chat Box & LMS, YouTube, Blog, MS Teams \\
\hline Feestions & MS Teams (live), Chat Box & MS Teams, Email, Blog \\
\hline Assessment & MS Teams (live), Chat Box & MS Teams, Email, LMS \\
& MS Teams (live) participation, & Online assignments \\
& On-line quizzes during the class & \\
\hline
\end{tabular}

*Microsoft Teams (live audio-based discussion session)

Next, I present the logistic support I had and the implementation of my e-learning plan. 


\section{Logistics Support}

Logistics support includes the equipment (i.e., computer, recording devices), software applications, training to use these applications, and ideal internet facilities. I have my laptop with all the necessary applications installed in it (including a microphone and speakers), and good internet service. I am also skilled in using these applications. The new application that the university used to regulate online teaching was Microsoft Teams (MS Teams). The university Information Technology (IT) department provided training manuals and videos to learn how to use MS Teams. A WhatsApp group and a technical support team (on MS Teams) was also formed to assist teachers. On the WhatsApp group, all the colleagues were supporting each other wherever required. On the teacher's end, I was satisfied that we were not left alone by the university.

I was concerned about the students. All of them had their laptops. They were good at using different applications. They were provided with books and related material in PDF format at the beginning of the semester. Now, for online classes, the university provided them technical support and access to install and use MS Teams on their laptops. All the students have good speed internet service. During my classes, only about $10 \%$ of students reported internet issues. However, it was temporary and was not related to internet disconnection.

It was good that both teachers and students were using their resources and getting support from the university wherever it was required. The first important challenge was successfully addressed with institutional support.

\section{Implementation}

As I said earlier, I had already finished about half of the course during the first half of the semester. The challenge was to implement the e-learning plan for the rest of the course (that we were supposed to complete conducting online classes). The university provided all possible support to teachers and students, including training to use software applications required for online teaching. It was now my responsibility to find the best possible way to implement my plan and manage online classes. I had a cognitive understanding of my students' learning approach. I enlisted the following major concerns that I was going to address while implementing my e-learning plan:

- I should not go for a major cognitive shift introducing an entirely different way of teaching. It is better to engage them with a familiar teaching method with some modification required to meet the need for synchronous and asynchronous learning.

- Whatever I upload on the internet should be easily available to download with moderate internet speed. For this purpose, the content should be available on multiple web-based platforms.

- The video content should be uploaded on a platform that offers user-friendly streaming.

- All the questions students may have should be answered in a way that is available to them $24 / 7$.

- I must ensure that students are attending and participating in online classes.

After enlisting these concerns, I started working with two basic thoughts in my mind. First, the lecture format and teaching method should be familiar to all students, similar to what they have already experienced during regular classes. Second, I should provide them multiple options to 
watch, download, and attend to the course content at their ease. I wrote an outline and lesson plan for my lecture. I prepared the lecture slides using Microsoft PowerPoint with emphasis on adding more visual content (such as illustrations and descriptive images). I recorded the lecture, taking care with my tone of voice and speed, as is required to prepare a video lecture. Screen recording was another option that I was able to use in Microsoft PowerPoint. However, I also used Windows Movie Maker to convert PowerPoint slides into a video. Windows Movie Maker was easy to use. I was able to add more slides, images, sounds, and video clips wherever required. It also provided options to save videos in different formats. Keeping in mind the concentration span of undergraduate students, I prepared a 20- to 40-minute video. To ensure easy access (and mobilefriendly access), I uploaded the video on my YouTube channel in the designated playlist. I also uploaded videos and related supplementary material on the LMS and MS Teams.

After uploading the lecture, I created two teams for two groups of students and added them on MS Teams. I ensured that all students had joined the team. I shared the timetable for the online class and decided to conduct one class of 90 minutes for each group once a week. The main objective of the class is to teach the selected topic and to engage students in discussion about the video lecture they had already watched. Questions, answers, and reflections were an important part of the discussion. To ensure students' participation, I prepared an online attendance sheet using MS Teams seeking following information:

- Have you watched the video? (Yes/No)

- Have you downloaded the content? (Yes/No)

- Have you read the relevant material, such as a textbook? (Yes/No)

- Give your comments, suggestions, and ask any question you have related to the topic? (Open ended question)

The information grabbed from this attendance sheet helped me to find out the percentage of students watching, downloading, and reading relevant text. Besides providing feedback and suggestions, I was able to understand and answer their questions that they could not ask during the class for any reason (such as some technical issue or shortage of time). I uploaded the answers to the topic-related questions on a blog page that was easily accessible to students, even if accessing it using their cell phones.

My e-learning implementation plan (Figure 3) worked well and I received positive feedback. In the first lectures, a few students asked for the lecture transcript to read, besides watching the video. All my video lectures uploaded on YouTube were in the English language. I taught them how to use YouTube's open transcript option to read and copy the lecture transcript. To facilitate more, I uploaded PowerPoint slides on the LMS and MS Teams.

\section{Students' Feedback}

After each class, I followed up on the number of students watching and downloading video lectures before class. On average, 63\% downloaded the video from the LMS or MS Teams, and 94\% watched it on YouTube. This $94 \%$ also included those who downloaded the video. 


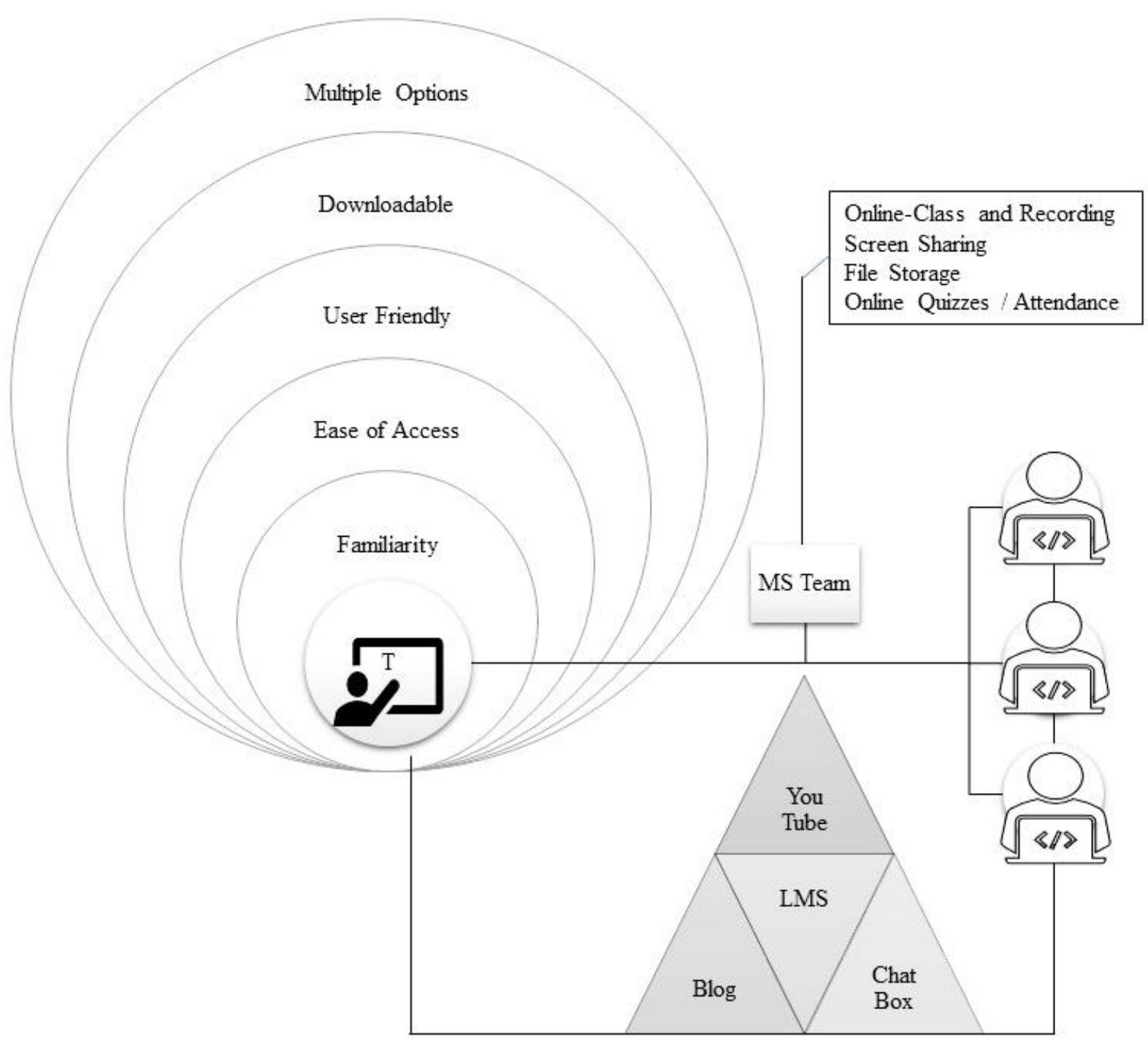

Figure 3: My e-learning implementation plan.

After three weeks, I asked the students to provide overall feedback on my e-learning plan and their online learning experience. To ensure their anonymity and freedom of response, I asked them to provide their opinion in an online form that would not ask them for any identifying information and would not fetch any email addresses. I received positive feedback and found that my objectives were successfully met as I perceived and as I practiced. Students liked the idea of YouTube videos and blog pages. As I mentioned earlier about my intention to use the YouTube channel, I found that YouTube videos were more accessible and easier to watch. For example, one of the students commented about YouTube videos, "the YouTube videos are good. They are not too long and not too short. They comprehensibly explained sufficient information". They were happy that they could watch the lecture and read the transcript before online class. "I can easily understand the content discussed in the video. I liked that subtitles were present in every video uploaded on YouTube," another student mentioned. After the online class they were able to find 
answers to their questions on blog pages. One of the students appreciated posting questions on the blog in these words,

That is great. You answer everyone's question in detail, and it reaches everyone. You paid attention to those questions that students were not able to ask during class due to internet connectivity issue or they were shy or could not ask for any other reason (anonymous student)

Students also appreciated the content being uploaded onto multiple digital platforms; that eased their access.

My overall quarantined teaching experience has been positive. I found that the objective I set were realistic and I met those objectives successfully. My plan worked well in the current situation.

\section{Conclusion}

Quarantined-at-home teaching was a new experience for me, and I assume the same for several others in the world who are struggling to offer a blended learning experience to the students. We, as teachers and students interacting in regular classes, have a level of cognitive satisfaction that we get with F2F teaching. Indeed, we cannot postpone the teaching and learning process in the current unpredictable situations. Blended learning is a good option when the physical classroom must be replaced with the online classroom. Our institutions are responsible to provide us logistic and pedagogical support to continue the teaching process through asynchronous and synchronous modes. We as teachers, however, are responsible to connect to our students in any possible way, leaving no student unattended. We should show reflexivity in our teaching approach and should follow up on our e-learning approach. In this article, I shared my experience and came up with the humble layman's solution that I found successful to maintain a teacher-student connection, likely more familiar to formal settings. We (both teacher and students) did not waste our time learning several technical tools to stay connected, and we used almost the same technology and platform as we did in our daily use. ACTS, which I focused on as my core objectives to lead my blended learning format, helped me to plan and implement e-learning for undergraduate students in line with my university and the HEC instructions.

\section{Achnowledgements}

I would like to thank Professor Dr. Salma Siddiqui (Head of the Department of Behavioural Sciences, NUST) and Professor Dr. Ashfaque Hassan Khan (Dean of the School of Social Sciences and Humanities, NUST) for their kind and timely support throughout the teaching process in our quarantined settings.

\section{References}

Al-alak, B. A., \& Alnawas, I. A. (2011). Measuring the acceptance and adoption of e-learning by academic staff. Knowledge Management \& E-Learning: An International Journal, 3(2), 201-221. https://doi.org/10.34105/j.kmel.2011.03.016 
AlJarrah, A., Thomas, M. K., \& Shehab, M. (2018). Investigating temporal access in a flipped classroom: procrastination persists. International Journal of Educational Technology in Higher Education, 15(1), 1-18. https://doi.org/10.1186/s41239-017-0083-9

Bailey, C. J., \& Card, K. A. (2009). Effective pedagogical practices for online teaching: Perception of experienced instructors. The Internet and Higher Education, 12(3-4), 152-155. https://doi.org/10.1016/j.iheduc.2009.08.002

Banditvilai, C. (2016). Enhancing students' language skills through blended learning. Electronic Journal of e-Learning, 14(3), 220-229.

Boelens, R., De Wever, B., \& Voet, M. (2017). Four key challenges to the design of blended learning: A systematic literature review. Educational Research Review, 22, 1-18. https://doi.org/10.1016/j.edurev.2017.06.001

Broadbent, J. (2017). Comparing online and blended learner's self-regulated learning strategies and academic performance. The Internet and Higher Education, 33, 24-32. https://doi.org/10.1016/j.iheduc.2017.01.004

Crawford-Ferre, H. G., \& Wiest, L. R. (2012). Effective online instruction in higher education. Quarterly Review of Distance Education, 13(1), 11-14.

Davis, F. D. (1989). Perceived usefulness, perceived ease of use, and user acceptance of information technology. MIS Quarterly, 13,(3), 318-339. https://doi.org/10.2307/249008

HEC (Higher Education Commission of Pakistan). (2020a). COVID-19-technology support committee (working paper). Retrieved from https://hec.gov.pk/english/HECAnnouncements/Documents LnCoVirus/Approved-Working-Paper.pdf

HEC (Higher Education Commission of Pakistan). (2020b). Why online education? Retrieved from https://hec.gov.pk/english/HECAnnouncements/Pages/Why-Online-Education.aspx

Kidd, T. T., \& Keengwe, J. (2010). Adult learning in the digital age: Perspectives on online technologies and outcomes. Hershey, PA: IGI Global.

Lai, M., Lam, K. M., \& Lim, C. P. (2016). Design principles for the blend in blended learning: A collective case study. Teaching in Higher Education, 21(6), 716-729. https://doi.org/10.1080/13562517.2016.1183611

Leo, J., \& Puzio, K. (2016). Flipped instruction in a high school science classroom. Journal of Science Education and Technology, 25(5), 775-781. https://doi.org/10.1007/s10956-016-9634-4

Lightner, C. A., \& Lightner-Laws, C. A. (2016). A blended model: Simultaneously teaching a quantitative course traditionally, online, and remotely. Interactive Learning Environments, 24(1), 224-238. https://doi.org/10.1080/10494820.2013.841262

Maycock, K. W., Lambert, J., \& Bane, D. (2018). Flipping learning not just content: A 4-year action research study investigating the appropriate level of flipped learning. Journal of Computer Assisted Learning, 34(6), 661-672. https://doi.org/10.1111/jcal.12274

McGee, P., \& Reis, A. (2012). Blended course design: A synthesis of best practices. Journal of Asynchronous Learning Networks, 16(4), 7-22. https://doi.org/10.24059/olj.v16i4.239

Mijatovic, I., Cudanov, M., Jednak, S., \& Kadijevich, D. M. (2013). How the usage of learning management systems influences student achievement. Teaching in Higher Education, 18(5), 506-517. https://doi.org/10.1080/13562517.2012.753049

Rogers, E. M. (2003). Diffusions of innovations (5th ed.). New York, NY: Free Press.

Shea, P., Pickett, A., \& Li, C. S. (2005). Increasing access to higher education: A study of the diffusion of online teaching among 913 college faculty. International Review of Research in Open and Distributed Learning, 6(2), 1-27. https://doi.org/10.19173/irrodl.v6i2.238 
Shiflett, K. H. (2014). The relationship between organizational culture and adherence to regulatory requirements for online programs (Unpublished doctoral dissertation). Pittsburgh, PA, University of Pittsburgh.

Singh, H. (2003). Building effective blended learning programs. Educational Technology, 43(6), 51-54.

Speak, C. (2020, March 31). How teachers in Italy have adapted to working remotely under quarantine. The Local. Retrieved from https://www.thelocal.it/20200331/how-teachers-in-italy-are-adapting-toworking-remotely-under-quarantine

Ssekakubo, G., Suleman, H., \& Marsden, G. (2011, October). Issues of adoption: Have e-learning management systems fulfilled their potential in developing countries? Proceedings of the South African Institute of Computer Scientists and Information Technologists Conference on Knowledge, Innovation and Leadership in a Diverse, Multidisciplinary Environment, 231-238. https://doi.org/10.1145/2072221.2072248

Sun, J. C. Y., Wu, Y. T., \& Lee, W. I. (2017). The effect of the flipped classroom approach to OpenCourseWare instruction on students' self-regulation. British Journal of Educational Technology, 48(3), 713-729. https://doi.org/10.1111/bjet.12444 